\title{
EFEKTIVITAS KONSELING POSITIF MENTAL TIME TRAVEL UNTUK MENGURANGI KECEMASAN IBU DALAM MENGHADAPI MENOPAUSE DI WILAYAH KERJA PUSKESMAS JEMBATAN KECIL
}

\author{
Desi Fitriani ${ }^{1}$, Wayterlis Apriani ${ }^{2}$ \\ Program Studi Kebidanan Program Sarjana Terapan STIKES Tri Mandiri Sakti Bengkulu ${ }^{12}$ \\ e-mail: ${ }^{1}$ fitriadesy120@gmail.com, ${ }^{2}$ iterapriani12@gmail.com
}

\begin{abstract}
Menopause is a process of transition from a productive period to a non-productive period. This period affects the psychological aspect, reminding him that he will grow old because his reproductive organs are no longer functioning and worries about other things that may arise accompanying the end of his reproductive period. This study aims to determine the effectiveness of positive mental time travel counseling to reduce maternal anxiety in dealing with menopause in the working area of the Small Bridge Public Health Center. This type of research is true experiments with a posttest-only control design approach. The population of this study were all mothers aged 40-50 years. The sample in this study were 96 people, 48 experimental groups and 48 control groups. The sampling technique was accidental sampling where the sample in the study was mothers aged 40-50 years who were in the area of the Small Bridge Health Center. The analysis technique taken is the Paired e t-test statistical test. Univariate results, namely the average anxiety of mothers in dealing with menopause in the group given positive mental time travel counseling is 10.19. The average maternal anxiety in dealing with menopause in the group that was not given positive mental time travel counseling was 19.29. The results of the bivariate analysis obtained a p-value of $0.000<0.005$. It was concluded that positive mental time travel counseling was effective in reducing maternal anxiety in dealing with menopause in the working area of the Small Bridge Public Health Center. It is hoped that positive mental time travel counseling can be used as an effort to improve psychological conditions for a good quality of life for postmenopausal women.
\end{abstract}

Keywords : Anxiety, Positive counseling mental time travel

\begin{abstract}
ABSTRAK
Menopause merupakan proses peralihan dari masa produktif menjadi masa non produktif. Masa ini mempengaruhi aspek psikologis, mengingatkan dirinya yang akan menjadi tua karena organ reproduksinya sudah tidak berfungsi lagi dan kekhawatiran terhadap hal-hal lain yang mungkin muncul menyertai berakhirnya masa reproduksinya. Penelitian ini bertujuan untuk mengetahui efektifitas konseling positif mental time travel untuk mengurangi kecemasan ibu dalam menghadapi menopause di wilayah kerja puskesmas jembatan kecil. Jenis Penelitian adalah true exsperiments dengan pendekatan posttest-only control design. Populasi penelitian ini adalah semua ibu yang berusia 40-50 tahun. Sampel dalam penelitian ini sebanyak 96 orang, 48 kelompok eksperimen dan 48 kelompok kontrol.Teknik pengambilan sampel accidental sampling dimana sampel pada penelitian yaitu ibu dengan usia 4050 tahun yang berada di wilayah puskesmas Jembatan Kecil. Teknik Analisis yang diambil adalah uji statistic Paired e t-test. Hasil Univariat yaitu rata-rata kecemasan ibu dalam menghadapi menopause pada kelompok yang diberikan konseling positif mental time travel adalah 10,19. Rata -rata kecemasan ibu dalam menghadapi menopause pada kelompok yang tidak diberikan konseling positif mental time travel adalah19,29. Hasil analisis bivariate didapatkan nilai $p$-value $0,000<0,005$. Disimpulkan konseling positif mental time travel berefektivitas untuk mengurangi kecemasan ibu dalam menghadapi menopause di wilayah kerja puskesmas jembatan kecil. Diharapkan dapat menjadikan konseling positif mental time travel sebagai salah satu upaya meningkatkan kondisi psikologis untuk kualitas hidup yang baik bagi ibu menopause.
\end{abstract}

Kata kunci: Kecemasan, Konseling positif mental time travel 


\section{PENDAHULUAN}

\section{Latar Belakang (Opsional)}

Menurut data World health organization (WHO) pada tahun 2017, wanita di dunia sekitar 107 juta wanita di perkirakan mengalami menopause, dari 78 juta wanita berusia 50 tahun ke atas menghabiskan hidupnya dalam keadaan pasca menopause, dan $40 \%$ dari pasca menopause tersebut tinggal di Negara berkembang dengan rata rata mengalami menopause pada usia 51 tahun. Pada tahun 2025, proporsi jumlah wanita yang menopause melonjak dari 107 menjadi 373 juta di Asia, dan dari 13 menjadi 46 juta di Afrika [1]

Wanita umumnya menghabiskan sepertiga terakhir dari hidup mereka dalam menopause, setelah tahun-tahun reproduksi mereka berakhir. Selama menopause, wanita mengalami berbagai gejala dan kondisi yang dapat diprediksi terkait dengan perubahan kadar hormon seks dan penuaan. Transisi menopause mendahului menopause beberapa tahun dan biasanya ditandai dengan ketidakteraturan siklus menstruasi dan hot flashes dan keringat malam. Setelah menopause, gejala genitourinari mendominasi, termasuk atrofi dan kekeringan vulvovaginal dan gejala saluran kemih bagian bawah, termasuk frekuensi buang air kecil, urgensi, dan nokturia. Pengobatan hormonal efektif untuk gejala vasomotor dan genitourinari, tetapi pemahaman tentang dampaknya terhadap penyakit kardiovaskular, disfungsi kognitif, dan depresi terus berkembang $^{[2]}$

Menurut data Kementrian Kesehatan RI diketahui bahwa jumlah penduduk perempuan di Indonesia pada tahun 2018 sebesar jumlah perempuan usia 40-44 tahun sebanyak 9.551.334 jiwa, usia 45-49 tahun sebanyak 8.657.332 jiwa, usia 50-54 tahun sebanyak 7.536.479 jiwa dan usia 55-59 tahun sebanyak 6.205.690 dan usia 60+ sebanyak 1.297.2878 hal ini menujukkan bahwa wanita pramenopoause dan wanita menopause sekitar $31,1 \%$ lebih dari seperempat dari penduduk wanita di Indonesia ${ }^{[3]}$

Menopause yang dikenal sebagai masa berakhirnya menstruasi, sering dianggap sebagai sesuatu yang menakutkan dalam kehidupan seorang wanita. Masa ini mempengaruhi aspek psikologis, mengingatkan dirinya yang akan menjadi tua karena organ reproduksinya sudah tidak berfungsi lagi dan kekhawatiran terhadap hal-hal lain yang mungkin muncul menyertai berakhirnya masa reproduksinya ${ }^{[4]}$

Banyak wanita merasa cemas menghadapi menopause karena mereka beranggapan bahwa wanita yang berusia lanjut akan mengalami hidup yang kurang sehat, kurang bugar dan tidak cantik lagi. Padahal, menopause merupakan suatu fase kehidupan yang harus dialami dan tidak dapat dihindari oleh setiap wanita. Menjadi tua memang hal yang sering ditakuti oleh para wanita, tetapi hal ini tidak berarti wanita kehilangan identitas kewanitaannya. Walaupun demikian, tidaklah dapat dipungkiri adanya aneka perubahan fisik dan emosi yang menyebabkan masa menopause merupakan masa yang membutuhkan penyesuaian diri. ${ }^{[5]}$

Fenomena yang terjadi di masyarakat sekarang ini menunjukkan bahwa banyak kaum ibu mengalami masalah dalam menghadapi menopause. Masalah-masalah yang sering dihadapi oleh kaum ibu antara lain adalah gangguan dalam kehidupan seksual suami istri, tanda-tanda fisik seperti keringat yang berlebihan dan rasa panas pada muka. Juga timbul perasaan-perasaan yang tidak menyenangkan, seperti perasaan cemas, sedih, marah, cemburu dan berbagai perasaan tidak nyaman muncul pada usia itu serta perasaan tidak berguna karena tidak bisa melahirkan anak lagi. Selain hal-hal tersebut, ketidaksiapan kaum ibu dalam menghadapi proses penuaan merupakan suatu masalah tersendiri ${ }^{[5]}$

Pada Penelitian "Group cognitive behavioural therapy of physical and psychological menopausal symptoms of Chinese women, delivered via Internet and mobile phone versus face to face: A protocol for a randomized non-inferiority trial". Hasil penelitian untuk memverifikasi kelayakan dan efek dari iGT pada sindrom menopause, perubahan suasana hati, dan kualitas hidup pada wanita menopause ${ }^{[6]}$

Konseling merupakan proses yang melibatkan perilaku individu partisipan dalam 
hal mana di dalamnya berkorelasi antara konselor dan klien serta unsur terkait seperti interaksi, situasi internal dan eksternal yang memengaruhinya.[7]

$$
\text { Atkinson (2008:426) menjelaskan }
$$

bahwa untuk mengatasi kecemasan diperlukan suatu perlakuan konseling yang langsung bersentuhan pada reaksi kognitif yang berorientasi kepada diri klien. Artinya konseling merupakan bagian penting yang dapat digunakan untuk menanggulangi masalah kecemasan yang dialami Menopause. PMTT merupakan salah satu kajian neurosains, karena adanya keterkaitan proses imajinasi dengan fungsi otak. Pinel (2012:279) mengungkapkan bahwa ingatan tentang pengalaman terletak pada korteks sensori topografik. Terkait dengan reexperiencing dan preexperience. [8]

\section{Tujuan Penelitian (Opsional)}

Penelitian ini bertujuan Mempelajari Efektifitas Konseling Positif Mental Time Travel Untuk mengurangi Kecemasan Ibu dalam menghadapi Menopause di wilayah kerja Puskesmas Jembatan Kecil.

\section{Hipotesis (Opsional)}

konseling positif mental time travel berefektivitas untuk mengurangi kecemasan ibu dalam menghadapi menopause di wilayah kerja puskesmas jembatan kecil

\section{METODE}

Penelitian ini dilaksanakan pada bulan 27 Juli s.d 27 Agustus 2021. Penelitian ini dilakukan di Wilayah Kerja Puskesmas Jembatan Kecil. Desain penelitian ini menggunakan metode true exsperiments, dengan pendekatan posttest-only control design. Penelitian Pretest-Postest design merupakan penelitian yang menggunakan dua kelompok yang dipilih secara random. Kelompok Pertama diberi perlakuan dan kelompok yang lain tidak diberi perlakuan. Populasi dalam penelitian ini adalah semua ibu yang berusia 40 sampai 50 tahun di Wilayah Kerja Puskesmas Jembatan Kecil tahun 2021. Sampel dalam penelitian ini sebanyak 96 orang, 48 kelompok eksperimen dan 48 kelompok kontrol.Teknik pengambilan sampel accidental sampling dimana sampel pada penelitian yaitu ibu dengan usia 40-50 tahun yang berada di wilayah puskesmas Jembatan Kecil.

\section{HASIL}

\section{Analisis Univariat}

Analisis Univariat digunakan untuk melihat nilai mean, standar deviasi, dan $95 \%$ CI for mean dari tingkat kecemasan ibu menghadapi Menopause sesudah diberikan perlakuan Konseling Positif Mental Time Travel untuk kelompok eksperimen dan untuk kelompok kontrol tidak diberikan Konseling Positif Mental Time Travel.

Tabel 1.

Rerata kecemasan ibu dalam menghadapi menopause pada kelompok eksperimen dan kelompok kontrol

\begin{tabular}{|c|c|c|c|c|c|}
\hline & & Mean & $\mathrm{N}$ & $\begin{array}{l}\text { Std. } \\
\text { Deviati } \\
\text { on }\end{array}$ & $\begin{array}{l}\text { Std. Error } \\
\text { Mean }\end{array}$ \\
\hline $\begin{array}{l}P \\
\text { ai } \\
r\end{array}$ & $\begin{array}{l}\text { Nilai HRS-A } \\
\text { (Kelompok } \\
\text { Eksperimen) }\end{array}$ & 10.19 & 48 & 2.312 & .334 \\
\hline 1 & $\begin{array}{l}\text { Nilai HRS-A } \\
\text { (Kelompok Kontrol) }\end{array}$ & 19.29 & 48 & 3.908 & .564 \\
\hline
\end{tabular}

Berdasarkan tabel 1 diatas menunjukan bahwa kecemasan Ibu dalam menghadapi menopause setelah dilakukan Konseling Positif Time Travel pada kelompok eksperimen didapatkan nilai ratarata 10,19 dan kecemasan Ibu dalam menghadapi Menopause pada kelompok control 19.29.

\section{Uji Normalitas}

One-Sample Kolmogorov-Smirnov Test

Unstandardized

Residual

\begin{tabular}{llr}
\hline $\mathrm{N}$ & & 96 \\
Normal & Mean & .0000000 \\
Parameters ${ }^{\mathrm{a} b}$ & Std. Deviation & .28768819 \\
Most Extreme & Absolute & .084 \\
Differences & Positive & .074 \\
& Negative & -.084 \\
Test Statistic & .084 \\
\hline Asymp. Sig. (2-tailed) & $.093^{\mathrm{c}}$ \\
\hline
\end{tabular}


Berdasarkan tabel diatas, diketahui nilai $\rho$-value $=0.093>0,05$ maka dapat disimpulkan data berdistribusi normal.

\section{Analisis Bivariat}

Analisis ini digunakan untuk melihat efektifitas konseling positif time travel untuk mengurangi kecemasan ibu dalam menghadapi menopause.

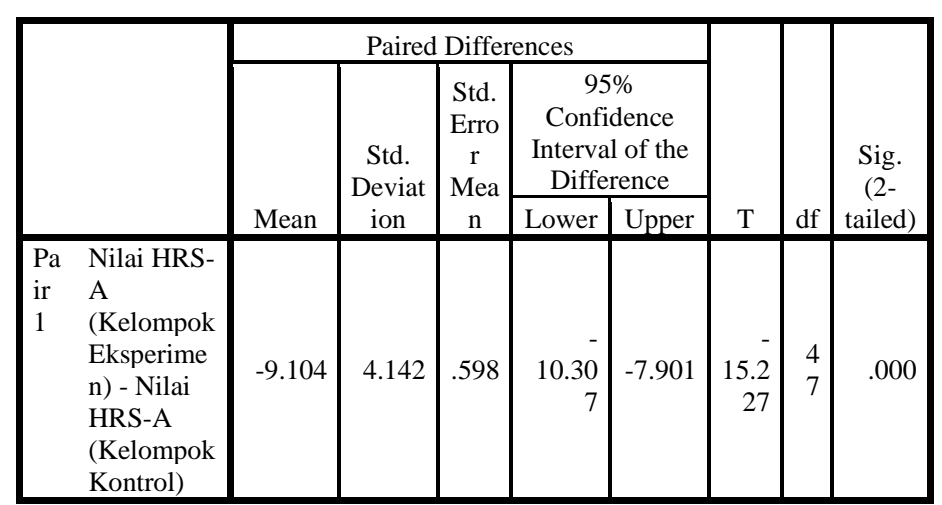

Berdasarkan tabel 3 hasil analisis nilai $p$-value $=0.000<0.005$ berarti signifikan ada perbedaan nilai kecemasan ibu dalam menghadapi Menopause pada kelompok eksperimen yang diberikan Konseling Positif Mental Time Travel dan Kelompok control yang tidak diberikan

\section{PEMBAHASAN}

Berdasarkan hasil penelitian menunjukan bahwa kecemasan Ibu dalam menghadapi Menopause setelah dilakukan Konseling Positif Time Travel didapatkan nilai rata-rata 10,19 dan kecemasan Ibu dalam menghadapi Menopause pada kelompok control 19.29. Kecemasan ibu pra menopause memang biasa terjadi sebab hal ini berhubungan dengan faktor yang mempengaruhi kecemasan, seperti faktor lingkungan, faktor emosi yang ditekan, faktor sebab-sebab fisik, dan juga faktor keturunan. Hal ini didukung, ketidakteraturan haid yang terjadi, secara bawah sadar meningkatkan kecemasan wanita bahwa daya tarik seksual dan fisiknya berkurang. Kecemasan adalah gejala yang tidak spesifik yang sering ditemukan dan sering kali suatu emosi yang normal. Kecemasan dapat timbul karena orang berusaha membuat sebuah keputusan sebelum memiliki pengetahuan yang cukup untuk dijadikan dasar keputusan mereka. ${ }^{[9]}$

Berdasarkan penelitian didapatkan ada perbedaan nilai kecemasan ibu dalam menghadapi Menopause pada kelompok eksperimen yang diberikan Konseling Positif Mental Time Travel dan Kelompok control yang tidak diberikan. Hal ini memang sesuai dengan tujuan KIE, yang merupakan suatu strategi dari metode pendidikan kesehatan dengan meningkatkan hubungan saling percaya dengan klien sehingga dapat membantu perubahan perilaku ke arah yang positif. konseling menjadi sebuah bentuk kreativitas yang dapat membantu konseli menyelesaikan masalah atau menemukan solusi dengan cara yang unik. Berbagai bentuk seni kreatif dalam konseling yang dapat digunakan konselor ${ }^{[10]}$

Tingkat kecemasan yang tinggi pada Menopause berdampak pada psikologis dan pisiologis. Faktor yang paling dominan penyebab kecemasan lansia adalah membayangkan peristiwa masa depan yang tidak menyenangkan karena ada pengalaman buruk dimasa lalu. Brown 83 et al., (2014) mengungkapkan bahwa menggunakan sistem memori yang memfasilitasi kenangan peristiwa masa lalu untuk memproyeksikan dan mensimulasikan peristiwa baru ke masa depan akan berpengaruh terhadap psikologis seseorang. Untuk itu, perlu adanya teknik yang dapat mengubah kenangan buruk masa lalu serta rasa was-was untuk menyonsong masa depan. Salah satu teknik yang telah terbukti efektif adalah konseling PMTT [11]

Berdasarkan hasil penelitian "Everyday Thoughts in Time: Experience Sampling Studies of Mental Time Travel" konseling PMTT efektif untuk mengatasi kecemasan 
dengan teknik positive mental time travel dapat menurunkan stress dalam 15 hari. Penelitian ini mengindikasikan bahwa tidak perlu waktu yang panjang untuk mengurangi kecemasan $^{[12]}$

\section{KESIMPULAN}

Rata-rata kecemasan Ibu dalam menghadapi Menopause pada kelompok eksperimen diberikan Konseling Positif Time Travel 10,19 dan kecemasan Ibu dalam menghadapi Menopause pada kelompok control 19.29. Konseling Positif Time Travel berefektivitas untuk mengurangi kecemasan Ibu dalam menghadapi Menopause di Wilayah Kerja Puskesmas jembatan Kecil. Hasil penelitian ini diharapkan dapat menjadi landasan bagi petugas kesehatan dalam menjalankan perannya sebagai pendidik kesehatan dan penyuluhan kesehatan dalam melaksanakan pendidikan kesehatan bagi ibu pra menopause yang berkaitan dengan masalah psikologis ibu dalam menghadapi menopause \& dapat digunakan sebagai referensi untuk penelitian lain yang berkaitan dengan kecemasan ibu dalam menghadapi Menopause.

\section{DAFTAR PUSTAKA}

[1] World Health Organization (WHO), "WHO reveals leading causes of death and disability worldwide: 2000-2019," World Heal. Organ., 2020.

[2] T. A. Takahashi and K. M. Johnson, "Menopause," Medical Clinics of North America. 2015.

[3] Profil Kesehatan Indonesia, Kementrian Kesehatan Republik Indonesia (KEMENKES RI). 2019. Data dan Informasi Profil Kesehatan Indonesia 2018. Jakarta: Ditjen P2P, Kemenkes RI 2019. 2019.

[4] Namora Lumongga Lubis, "Psikologi Kespro.
Wanita dan Perkembangan Reproduksi : Ditinjau dari Aspek Fisik dan Psikologisnya," PT. Fajar Interpratama Mandiri, 2016. Irfan, "Faktor Determinan Kejadian Menopause - Google Books," Media Sains Indonesia, 2021.

[6] D. Li, J. Kong, Y. Yang, S. Wang, J. Wu, and J. Chao, "Group cognitive behavioural therapy of physical and psychological menopausal symptoms of Chinese women, delivered via Internet and mobile phone versus face to face: A protocol for a randomized non-inferiority trial," Maturitas, 2019.

[7] Mulawarman and E. Munawaroh, "Psikologi Konseling: Sebuah Pengantar bagi Konselor Pendidikan," Psikol. Konseling Sebuah Pengantar Bagi Konselor Pendidik., 2016.

[8] A. Dkk., "Pengantar psikologi (Edisi 11, Jilid 1).Batam : Interaksara.," Ji, 2018.

[9] D. F. Annisa and I. Ifdil, "Konsep Kecemasan (Anxiety) pada Lanjut Usia (Lansia)," Konselor, 2016.

[10] M. Keyes and P. J. Wilson, "Guidance Counseling," in Resources for Educational Equity, 2018.

[11] A. D. Brown et al., "Episodic and semantic components of autobiographical memories and imagined future events in post-traumatic stress disorder," Memory, 2014.

[12] R. F. Baumeister, W. Hofmann, A. Summerville, P. T. Reiss, and K. D. Vohs, "Everyday Thoughts in Time: Experience Sampling Studies of Mental Time Travel," Personal. Soc. Psychol. Bull., 2020. 